\title{
Road Surface Automatic Identification System With Combination Pothole Detection Method and Z-Diff Method On Android Smartphone
}

\author{
Siti Asmiatun ${ }^{1}$, Nur Wakhidah ${ }^{2}$, Astrid Novita Putri ${ }^{3}$ \\ \{siti.asmiatun@usm.ac.id ${ }^{1}$,ida @usm.ac.id ${ }^{2}$, astrid@usm.ac.id ${ }^{3}$ \} \\ Information Technology Study Program, Faculty of Information Technology and Communication, \\ Semarang University ${ }^{123}$, Soekarno-Hatta Street Tlogosari Semarang $50196^{123}$
}

\begin{abstract}
The road condition in Indonesia especially in Semarang is often experiencing damage in a rainy season. If the condition is not fixed immediately, it can inflict harms to the road user such as raising the fuel usage and the vehicle treatment and the worst harm is threatening the safety traffic. The solution of these problems is providing an up-to-date information about the road surface condition so that the local institution can do a road improvement immediately. This research discusses the data collection of the road condition using accelerometer censor in a smartphone. The censor accelerometer will record data based on the tool movement. To record the data from the censor accelerometer needs a method. This research develops a system which uses a system of the censor accelerometer to identify the road surface condition using pothole detection method and Z-Diff. The two method combinations result $74 \%$ of accuracy level, and it means that the system has high enough accuracy level in identifying a damage road or the one needs improvement. With the availability of the damage road location the work of transportation department of Semarang is hoped to make an immediate improvement to fix the road condition.
\end{abstract}

Keywords: Road, Surface, Automatic, Smartphone, Accelerometer, Pothole, Z-Diff.

\section{Introduction}

Indonesia is a two-seasons country where the rainy season and the dry season occur. When the rainy season starts, a lot of road conditions in Indonesia especially in Semarang experience damage in the road surface. The low quality of the road condition inflicts loss for the road user and it causes damage to the vehicle too because of the raising of the fuel usage, the spending of higher expenses for the vehicle treatment, and the lacking of comfort in riding the vehicle, even the worst one is threatening the road-trip safety [1]. The information about the road surface condition not only gives benefit to the users but also helps them to avoid the damage road so that they can take an alternative road.

The escalation of the traffic activities happens because the sheer volume of the road users is rising up too. So, knowing real time information about the road condition which is going to be passed contributes a considerable advantage to the road users. In a local regulation, the city estimation to repair the damage road is restrained, and then the information related to determining which road needs to have an immediate upgrading is highly needed [2]. The research focusing in detecting the damage roads and monitoring the traffic become the major 
subjects in many researches recently. Many researches use smartphone as a tool to collect the data because the cost is relatively cheaper and the feature is easier to be used [1]. To collect the data, a special censor is usually used for example GPS, Accelerometer, and the traffic camera $[3]$.

To record the data of the damage road, many researches utilize GPS and accelerometer. From that recording data, the data will then be proceeded again using a certain method. Determining the road surface condition requires a highly carefulness because the data which is recorded have to be able to differentiate whether the road anomaly which is detected is truly the damage road and need to be fixed or it is just a bump of the road. On the other hand, the data resulted from the censor depends on the speed of the vehicle, the tool position in the vehicle, and the brake pad in the vehicle used to slow it down. Off course, it needs detail and thorough research so that the censor is able to record the data which roads need to have an improvement. Some previous researches have been used pothole detection algorithm to identify the damage road surface and it results $90 \%$ of accuracy [2] and in other researches use z-diff algoritm which results $92 \%$ of accuracy [4]. Meanwhile this research aims to develop a system using accelerometer censor with combining pothole detection algorithm method and z-diff algorithm. It is hoped those two methods can sort out the data of road locations which is required to be repaired through accelerometer censor in smartphone. So, with the information gained by the two methods the transportation department in Semarang can improve its work to upgrading the road immediately.

\section{Methodology \\ 2.1. Pothole Detection Algoritm}

In this part, we will explain about pothole detection algorithm. Pothole detection algorithm is developed to detect the anomaly resulted from the accelerometer censor data. Basically, the data resulted from the accelerometer censor is the data gained from data acceleration [2]. The data acceleration is able to recognize various road surface anomalies such as hole, drain hole, sidewalk, railway system, and road connection. The driver behavior affects the value of data acceleration, for example circling, turning, sudden breaking, and others [2]. The road identification needs some required variables, so it can produce data as needed. Pothole detection algoritm is the algoritm that can filter some road anomalies like figure 1 below [5] [6]:

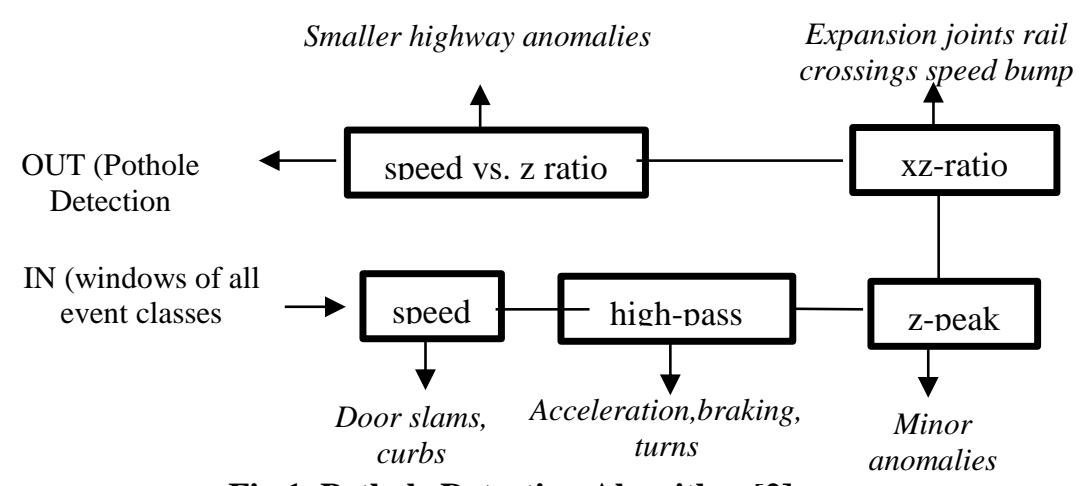

Fig.1. Pothole Detection Algorithm [2] 
The following description of the stages of figure 2 above :

a. Speed: it is the stage which records the data acceleration according to the speed, if the speed is zero or the vehicle runs slowly then the data is not be recorded.

b. High Pass : high pass will eliminate the value of data acceleration of low frequency value in each axis- $x$ and axis- $z$ that come in. The low frequency is affected by bending, breaking, turning, and little movement on the tool.

c. Z-Peak : determining a threshold level $(t z)$ in axis-z and eliminate all data which exceed from the threshold level $(t z)$.

d. XZ-Ratio : comparing the axis- $x$ and axis- $z$ that can generate $t x$ value. The data will be deleted if $\frac{x}{z} \leq t x$.

e. Speed Vs z Ratio : comparing the speed and the axis- $\mathrm{z}$ with the formula $\mathrm{z} \leq t s x$ speed.

\subsection{Z-Diff Algorithm}

Alghoritm Z-Diff is the algoritm which considers the dissent of the value on the Z-Axis which is generated from the accelerometer. Because the value of the axiz Z-Axis is experiencing many declines and rises caused by the speed value between time $t_{i, j-1}$ and time $t_{i, j}$. This algoritm requires the threshold value to detect the hole. Therefore, this study retrieves the largest value of velocity of variation of $\mathrm{z}$-axis accelerometer data through a pothole in experimental runs. The threshold value is obtained from the minimum $\mathrm{Z}$-axis of the maximum $\mathrm{Z}$-Axis in each experiment. The formula used to calculate the selected $Z$-axis value is as follows [7]:

$$
\theta_{2}=\min \max \frac{\left|g_{a, j, i}-g_{a, i, j-1}\right|}{t_{i, j}-t_{i, j-1}}
$$

Then after obtaining the threshold value $\left(\theta_{2}\right)$, if the value $f_{2}\left(g_{a, i, j}\right)$ is 1 from the value $\left|g_{a, i, j}-g_{a, i, j-1}\right| / t_{i, j}-t_{i, j-1}$ is larger than $\theta_{2}$ then pothole detected. The formula which is used is as follows [7]:

$$
\begin{gathered}
f_{2}\left(g_{a, i, j}\right)=\left\{\begin{array}{c}
1, \quad \frac{\left|g_{a, i, j}-g_{a, i, j-1}\right|}{t_{i, j}-t_{i, j-1}} \geq \theta_{2} \\
\text { other },
\end{array}\right. \\
\text { Where } \mathrm{a}=1,1 \leq i \leq n, i € N, j \geq, j \in N
\end{gathered}
$$

Notation :

Where $\mathrm{a}=1,1 \leq i \leq n, i € N, j \geq, j € N$

$g_{a, j, i}:$ The acceleration of the $a$ th axle of the $j$ th record in the $i$ th run

$t_{i, j} \quad:$ The timestamp of the $j$ th record in the $i$ th run

\subsection{Our Approach}

This research is combining two pothole detection methods and Z-Diff The combination steps we used are the following: 


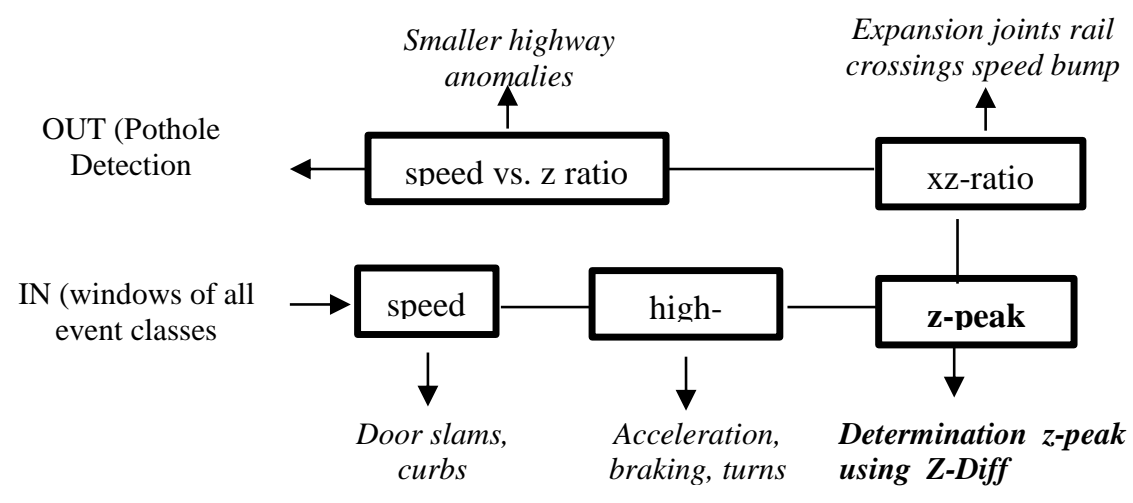

Fig.2. Combine Pothole Detection and Z-Diff Algorithm

The following description of the stages of figure 2 above :

a. Speed: it is the stage which records the data acceleration according to the speed, if the speed is zero or the vehicle runs slowly then the data is deleted.

b. High Pass : high pass will eliminate the value of data acceleration of low frequency value in each axis- $x$ and axis- $z$ that come in. The low frequency is affected by bending, breaking, turning, and little movement on the tool.

c. Z-Peak : determining the threshold value $(t z)$ in the axis $\mathrm{Z}$ by using the Z-Diff algorithm. Then eliminate all data which exceed from the threshold value $(t z)$.

d. XZ-Ratio : comparing the axis-x and axis-z that can generate $t x$ value. The data will be deleted if $\frac{x}{z} \leq t x$.

f. Speed Vs z Ratio : comparing the speed and the axis-z with the formula $\mathrm{z} \leq t s x$ speed.

\section{Results and Discussion}

\subsection{Data Collection}

The data used in this research was taken from the road located in East Semarang. The dataset collection through an Android cell phone is placed in the driver pocket. The dataset consists of the value of the axis $\mathrm{x}, \mathrm{y}, \mathrm{z}$ from accelerometer, latitude and longitude, and speed to know the vehicle velocity. Thoses values is used to identify the road surface and to filter the road surface which is not included damage road. 


\subsection{System Interface}

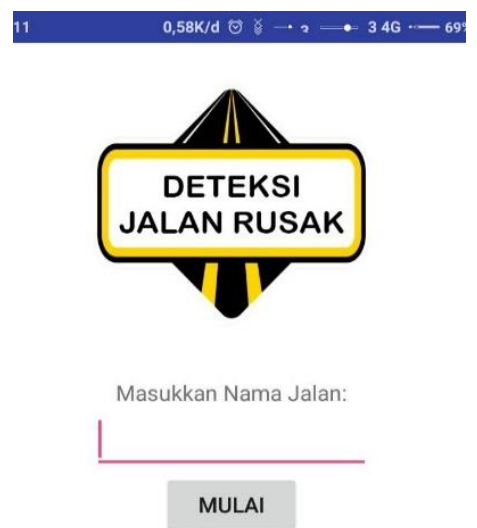

Fig.3. Main page between face

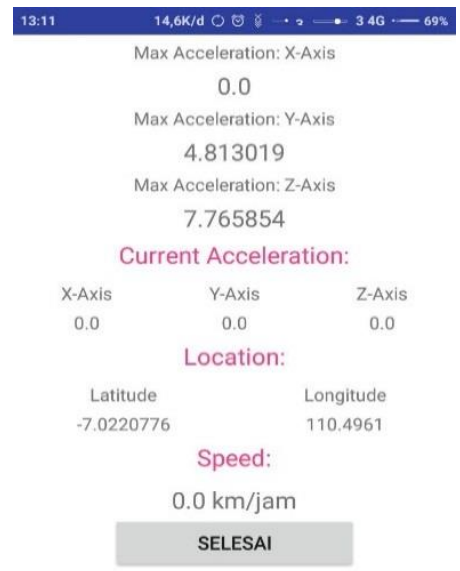

Fig.4. The process of Data Recording

Figure 3 shows the main page from the android application. Display this work to determine the name of the road to be identified. Then, after typing the name of the road, the users must press the start button to begin recording the road surface identification data. Figure 4 is the page which is used to read the value of axis $\mathrm{x}, \mathrm{y}$, and $\mathrm{z}$ from the accelerometer recording result. In this page, there are latitude and longitude to record the road surface and the speed to record the speed of the vehicle. The result of the data recording will be exported to the .xls type file.

The pothole detection and Z-Diff algorithm are applied when system is recording data. The data exported into the .xls file is the data have been sorted using the pothole detection algorithm and Z-Diff. The stages of the data sorting of the data recording application are as follows:

a. Speed : This stage records the data based on the speed, the speed limit that is recorded have to $\geq 10 \mathrm{~km} /$ hour.

b. High Pass : high pass will eliminate the value of data acceleration of low frequency value in each axis- $x$ and axis-z that come in. The low frequency is affected by bending, breaking, turning, and little movement on the tool. The minimum limit which is determined in the axis $\mathrm{x}$ is $\mathrm{x} \geq 0$ and axis $\mathrm{z}$ is $\mathrm{z} \geq 10$.

c. Z-Peak : determining the threshold value $(t z)$ in the axis $\mathrm{Z}$ by using the Z-Diff algorithm. Then eliminate all data which less than the threshold value $(t z)$. The threshold $\left(\theta_{2}\right)$ value is obtained from the minimum $\mathrm{Z}$-axis of the maximum $\mathrm{Z}$-Axis in each experiment, then calculated with the formula $z-z-1 / t-t-1$. And then to filter the data if $z-z-1 / t-t-1 \geq \theta_{2}$ so the data will be recorded.

d. XZ-Ratio : comparing the axis- $\mathrm{x}$ and axis-z that can generate $t x$ value. The data will be deleted if $\frac{x}{z} \leq t x$.. This research experiment is using $t x=0,257$

e. Speed Vs z Ratio : comparing the speed and the axis-z with the formula $\mathrm{z} \leq t$ s $x$ speed. The $t s$ value which is used in this experiment is 0,008 . 


\subsection{Result of Road Surface Identification}

This stage is discussing the result of the implementation of Pothole detection method and ZDiff. Both methods are applied on the system that uses the accelerometer censor. It aims to sort out the accelerometer data censor. That data is used to identify the road surface which needs to be fixed so that it can improve the work of Semarang transportation department to fix the road immediately. The dataset collection is gathered through the system using the accelerometer censor in the android cell phone. The result of data collection is used to identify the road surface which needs to be fixed especially in the East Semarang region. The data are shown as follows:

Table 1.The Identification Result of Road Surface in East Semarang Region

\begin{tabular}{lll}
\hline Region & Name of the Road & Number of Points \\
\hline Muktiharjo Lor & Jl. Sendang Indah Raya & 26 \\
& Jl. Muktiharjo Raya & 0 \\
Palebon & Jl. Palebon Raya & 3 \\
Bangetayu Wetan & Jl. Al Barokah & 4 \\
Tlogosari Kulon & & 26 \\
Tlogosari Wetan & & 32 \\
Gayamsari & Jl. Slamet Riyadi & 1 \\
Pedurungan & Jl. Bridjen Sudiarto & 2
\end{tabular}

The system identifies the road surface with the pothole method and Z-Diff. The data is collected in every sub-district in East Semarang. From the table 1 above 94 points of locations are detected by the system. The data was taken from several roads which the level of the damage is high in the sub-district of East Semarang especially in the location of Gayamsari, Genuk, and Pedurungan. The location point of the damage road detected by the system can be illustrated through the following graph:

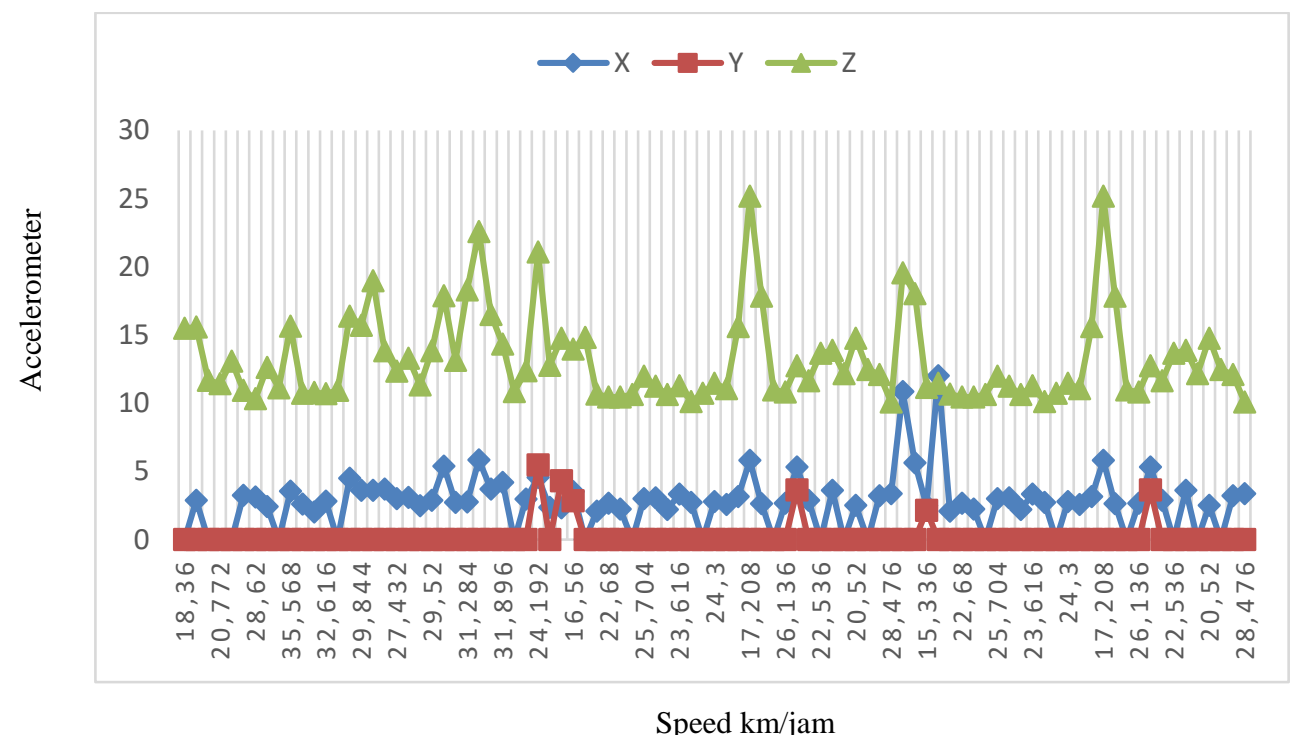

Fig.5. Accelerometer Reading 
The figure 4 above shows the result of data collection from the accelerometer censor in several sub-districts of East Semarang. The graph shows the value of axis $\mathrm{x}, \mathrm{y}$, and $\mathrm{z}$ which is recorded in different velocity. The vehicle velocity affects the process of data sorting since the method used is using the speed $\geq 10 \mathrm{~km} /$ hour. So, if the traffic jam is occurred in the road, it will impede the data collection of the damage road.

\subsection{Measurement Accuracy}

To measure the ability of the system in identifying the road surface, this research will apply the calculation using precision, recall and F-Measure [4]. This research applies a road trial in several sub-district regions in East Semarang. From the trial this research uses 67 points of the damage road dispersing in the sub-district of Gayamsari, Genuk, and Pedurungan. From the trial system, it records the data 94 points of the damage road successfully. The following is the matrix of the trial:

Table 2.Matrix of Data Collection Result

\begin{tabular}{lll}
\multicolumn{2}{l}{ Table 2.Matrix of Data Collection Result } \\
\hline Type & True & False \\
\hline The damage road & 59 & 35 \\
$\begin{array}{l}\text { Not the damage } \\
\text { road }\end{array}$ & & 5
\end{tabular}

$$
\begin{aligned}
& \text { Recall }=\frac{59}{59+35}=0,627 \\
& \text { Precision }=\frac{59}{59+5}=0,921 \\
& \text { F-Measure }=\frac{2 * \text { Recall } * \text { Precision }}{\text { Precision }+ \text { Recall }}=\frac{2 * 0,627 * 0,921}{0,627+0,921}=\frac{1,154}{1,548}=0,745
\end{aligned}
$$

The result above shows the recall accuracy value is $63 \%$, precision $92 \%$ dan results F-Measure as much as $74 \%$, it means that the system has a high enough accuracy in identifying the damage road or the road that required to be fixed. It is happened because the road is very crowded when the data is collected.

\section{Conclusion}

The information of the road surface condition is very useful to the road users and the local institution. That information can be used to reduce the traffic problems such as the traffic accident. This research develops a system which takes an advantage of accelerometer censor to 
identify the road surface condition using the pothole detection method and Z-diff. The implementation of the two methods can sort out the data recorded by the accelerometer censor so that the system can filter which the road surface condition needs to be fixed. The system is equipped by the GPS censor that can give information which the road location needs to be fixed. System experiments performed in the region of East Semarang which consists of the sub-district of Gayamsari, Genuk, and Pedurungan. From the experimental results the system can identify 94 locations of the damage roads and needs to be repaired. The accuracy level resulted from the system is $74 \%$, it means that the system is stable enough in identifying the road surface condition. For further research development, it is hoped to make interface that shows a map location from the data collection and can improve the accuracy using the different method.

Acknowledgments. This research is supported by the Ministry of Research, Technology, and Higher Education. We would like to express our gratitude on the support and encouragement so we can conduct this research smoothly. We hope that the result of our study gives contribution to the people of Indonesia.

\section{References}

[1] P. B. Lanjewar, R. Sagar, R. Pawar, J. Khedkar, and G. Kunal, "Road Bump and Intensity Detection using Smartphone Sensors," Int. J. Innov. Res. Comput. Commun. Eng., vol. 4, no. 5, pp. 9185-9192, 2016.

[2] J. Eriksson, L. Girod, B. Hull, R. Newton, S. Madden, and H. Balakrishnan, "The pothole patrol: using a mobile sensor network for road surface monitoring," Proceeding 6th Int. Conf. Mob. Syst. Appl. Serv. - MobiSys ’08, p. 29, 2008.

[3] V. Akinwande, O. Bello, K. Adewole, and A. Akintola, "Automatic and real-time Pothole detection and Traffic monitoring system using Smartphone Technology Automatic and real-time Pothole detection and Traffic monitoring system using Smartphone Technology," Int. Conf. Comput. Sci. Res. Innov. (CoSRI 2015), no. August, 2015.

[4] A. Mednis, G. Strazdins, R. Zviedris, G. Kanonirs, and L. Selavo, "Real time pothole detection using Android smartphones with accelerometers," 2011 Int. Conf. Distrib. Comput. Sens. Syst. Work. DCOSS'11, 2011.

[5] T. Kim and S.-K. Ryu, "Review and Analysis of Pothole Detection Methods," J. Emerg. Trends Comput. Inf. Sci., vol. 5, no. 8, pp. 603-608, 2014.

[6] R. Hartono, Y. Wibisono, and R. A. Sukamto, "Damropa ( Damage Roads Patrol ): Aplikasi Pendeteksi Jalan Rusak Memanfaatkan Accelerometer pada Smartphone,” pp. $1-6,2014$.

[7] H.-W. Wang, C.-H. Chen, D.-Y. Cheng, C.-H. Lin, and C.-C. Lo, "A Real-Time Pothole Detection Approach for Intelligent Transportation System," Math. Probl. Eng., vol. 2015, pp. 1-7, 2015. 